\title{
Recurrence risk after Ivor Lewis oesophagectomy for cancer
}

\author{
Mael Chalret du Rieu', Thomas Filleron², Benoit Beluchon', Marine Humeau', Charles-Henri Julio', Eric Bloom', \\ Laurent Ghouti ${ }^{1}$, Sylvain Kirzin ${ }^{1}$, Guillaume Portier ${ }^{1}$, Bernard Pradère ${ }^{1}$ and Nicolas Carrère ${ }^{1 *}$
}

\begin{abstract}
Objective: The aim of this study was to analyze the profile of tumor recurrence for patients operated on for cancer of oesophagogastric junction or oesophagus by Ivor-Lewis oesophagectomy.

Methods: Patients undergoing potentially curative Ivor-Lewis oesophageal resection between January 1999 to December 2008 at a single center institution were retrospectively analyzed. Their clinical records, details of surgical procedure, postoperative course, pathological findings, recurrence and long term survival were reviewed retrospectively. Univariate and multivariate survival analyses were performed.

Results: One hundred and twenty patients were analyzed. Fifty three patients (44\%) presented recurrence during median follow-up of 58 months. Five-year relapse free survival (RFS) rate was 51\% (95\%Cl= [46; 65\%]). On multivariate analysis, $\mathrm{pT}$ stage $>2(\mathrm{HR}=2.42,95 \% \mathrm{Cl}=[1.22 ; 4.79] \mathrm{p}=0.011)$, positive lymph node status $(\mathrm{HR}=3.69 ; 95 \% \mathrm{Cl}=[1.53$; 8.96] $p=0.004)$ and lymph node ratio $>0.2(H R=2.57 ; 95 \% C l=[1.38 ; 4.76] p=0.003)$ were associated with a poorer RFS and their combination was correlated to relapse risk. Moreover, preoperative tumor stenosis was associated with an increased risk of local recurrence $(H R=3.46 ; 95 \% \mathrm{Cl}=[1.38 ; 8.70] \mathrm{p}=0.008)$ whereas poor or undifferentiated tumor was associated with an increased risk of distant recurrence ( $H R=3.32 ; 95 \% \mathrm{Cl}=[1.03 ; 10.04] \mathrm{p}=0.044)$.

Conclusion: $\mathrm{PT}$ stage $>2$, positive lymph node status and lymph node ratio $>0.2$ are independent prognostic factors of recurrence after Ivor-Lewis surgery for cancer. Their combination is correlated with an increasing risk of recurrence that may argue favorably, in addition with preoperative tumor stenosis assessment, for adjuvant treatment or reinforced follow-up.
\end{abstract}

Keywords: Oesophageal carcinoma, Oesophagectomy, Ivor-Lewis, Lymph node ratio, Tumor stenosis

\section{Background}

Oesophageal cancer is a major public health concern as it is the fourth cause of cancer death after lung, colorectal and prostate cancers. Without contraindication of resectability or operability, surgery is the standard treatment of curative intent. However, in spite of optimal R0 resection, overall 5 -year survival is poor, about 20 to $30 \%$, because of frequent tumor recurrence [1]. Thus, exclusive chemoradiotherapy has become an alternative to surgical treatment, with a comparable overall survival in locally advanced squamous cell carcinoma [2,3]. However, ratio between adenocarcinoma and squamous cell carcinoma

\footnotetext{
* Correspondence: carrere.n@chu-toulouse.fr

${ }^{1}$ Department of Digestive Surgery, Toulouse Purpan University Hospital,

Toulouse III University, place du Dr Baylac, 31059 Toulouse, France

Full list of author information is available at the end of the article
}

incidence is changing with an increasing incidence of adenocarcinoma developed on Barrett oesophagus in Western countries [4]. Regarding adenocarcinoma, combination of neo-adjuvant treatment seems to provide improved survival despite of its own morbi-mortality [5]. Study of tumor relapse could therefore allow adaptation and targeting perioperative treatment to patients with high risk of recurrence. The aim of this study was to analyze the profile of tumor recurrence in a homogenous group of patients operated on for cancer of oesophagogastric junction or oesophagus by Ivor-Lewis oesophagectomy.

\section{Methods}

From January 1999 to December 2008, 120 consecutive patients underwent an Ivor-Lewis oesophagectomy for cancer at a single institution. Their clinical records were

\section{Biomed Central}


reviewed retrospectively for age, sex, Body Mass Index (BMI), nutritional factors, American Society of Anesthesiologists (ASA) score, symptoms at diagnosis, preoperative treatment, details of the surgical procedure, pathological findings, postoperative course, recurrence and long term survival. The research was carried out in compliance with the Helsinki Declaration and approved by the Comité de Protection des Personnes (CPP) Sud Ouest (Toulouse, France).

\section{Preoperative evaluation}

Operability and resectability criteria were those usually used in oncologic guidelines [6]. All surgical indications were validated in pluridisciplinary meeting. Endoscopy, computed tomography and barium swallows were systematically performed. Ultrasonographic endoscopy (EUS) was performed systematically as soon as it was technically available and when there was no non-traversable strictures. Positron emission tomography (PET) was done depending on the suspicion of metastatic extension. Features of lymph nodes on EUS and computed tomography, including size $1 \mathrm{~cm}$ or more, rounded shape, well demarcated borders, and heterogeneous patterns, were used to describe the nodes as benign or malignant.

Preoperative tumor stenosis was defined as a difficulty or inability for the fiberscope $(11.6 \mathrm{~mm}$ standard diameter) to pass through the lesion and/or at least a hemicircumferential narrowing light on barium swallow (both sides of the oesophagus narrowed by tumor noticed on at least one radiologic incidence).

Neo-adjuvant chemotherapy (CT) (Platin and 5 Fluorouracil) or chemoradiotherapy (CRT) (45 to $50 \mathrm{~Gy}$ and concomitant Platin/5 fluorouracil chemotherapy) was delivered in case of locally advanced cancer (T stage $\geq 3$ and/or N stage $\geq 1$ ). CRT was preferred for high volume tumors and/or for limited resection margins.

Clinical response was defined by regression of dysphagia and tumor size on post induction computed tomography. Endoscopic control, EUS nor PET were not routinely performed.

Immunonutrition was systematically delivered for seven preoperative days.

\section{Surgical procedure}

Conventional orotracheal intubation was performed without selective bronchial intubation. Gastrolysis was done through laparoscopy or midline laparotomy. Thoracotomy was done through a right posterolateral thoracotomy in the fifth intercostal space. Gastric transplant was created in the chest and anastomosed mechanically to the oesophagus. An extended upper abdominal lymphadenectomy was routinely performed comprising enbloc resection of the nodal tissue along the common hepatic and proximal splenic arteries together with that at the origins of the left gastric artery and celiac axis.
The lesser omentum was divided, encompassing the nodes along the lesser curve and an en-bloc hiatal dissection was performed removing the left and right paracardial stations and the respective crura. Within the thorax, standard lymphadenectomy was routinely performed that comprised middle and lower paraoesophageal nodes, paratracheal, carinal, left and right bronchial nodes and left recurrent laryngeal nerve chain. No cervical lymphadenectomy or three-field lymphadenectomy was undertaken even for tumors of middle third oesophagus. Patients were extubated in recovery room and then transferred to the ward.

\section{Postoperative data}

All tumors were staged post surgically by the TNM classification system of the American Joint Committee on Cancer 2002 for oesophageal or gastric cancer depending on tumor localization. The resection was designated R0 when it was thought that both macroscopic and microscopic clearance had been achieved; R1 when it was microscopically incomplete (margin inferior to one millimeter), and there was histologic evidence of invasion of the longitudinal or lateral margins; and R2 when it was macroscopically incomplete, with macroscopic residual tumor after surgery. Median lymph node ratio was defined by the ratio between number of positive lymph nodes and number of resected lymph nodes.

Operative mortality and morbidity was defined as any death or complication during the first 30 days after operation. A major complication was defined as any complication $>3$ on Clavien Dindo classification.

Follow up data were obtained from patient charts, tumor registry and referring physicians. A clinical examination was carried out every three to six months for three years. Thoraco-abdominal computed tomography was performed at least twice a year for 3 years or according to symptoms. Endoscopy was done in case of dysphagia.

For recurrence study, final date of follow-up was scheduled for March 31, 2010. Histologic, cytologic, or unequivocal radiologic proof was required before recurrence was diagnosed. Recurrence was classified into three categories: local recurrence (occurring at the surgical resection site or on cervical site), distant recurrence (in case of distant metastasis) and disseminated (in case of local and distant recurrence). Operative deaths and deaths that were not related to cancer were included in the survival statistics.

\section{Statistical analysis}

Data were summarized by frequency and percentage for categorical variables and by median and range for continuous variables. All survival times were calculated from the date of surgery. Relapse free survival (RFS) and 
overall survival (OS) were estimated by the KaplanMeier methods using the following first-event definitions: loco-regional or distant recurrence for relapse free survival and death from any cause for overall survival. Univariate analysis was performed using the LogRank test. The following three step algorithm using Cox proportional hazard modeling was performed:

Step 1: Influence of pre-operative variables with a $\mathrm{p}$-value $<0.05$ in univariate analysis was evaluated. Step 2: Influence of pathological variables with a $\mathrm{p}$-value $<0.05$ in univariate analysis was evaluated. Step 3: Influence of pre-operative and pathological variables statistically significative in step 1 and 2 was evaluated.

Competing risks multivariate analysis was conducted using the Fine \& Gray model in order to evaluate the influence of different variables on the cumulative incidence in the presence of competing risks (i.e local recurrence vs distant relapse).

All p-values reported were two-sided. For all statistical tests, differences were considered significant at the 5\% level. Statistical analyses were performed using the STATA 10.0 software.

\section{Results}

\section{Preoperative results}

One hundred and twenty patients were included. Median age at surgery was 62 years [27-79 years] (Table 1). Sex ratio male: female was 4: 1 . Dysphagia was the main symptom (68\%) and $16 \%$ of patients were asymptomatic among them 11.6\% were diagnosed for Barrett oesophagus follow-up and $5 \%(\mathrm{n}=6)$ on an examination prescribed for other indication. Severe weight loss (weight loss exceeding $10 \%$ of usual weight in one month or $15 \%$ in six months) was present in $20 \%$ of patients as $32 \%$ were overweight $\left(\mathrm{BMI}>25 \mathrm{Kg} / \mathrm{m}^{2}\right)$ and $6 \%$ were obese $\left(\mathrm{BMI}>30 \mathrm{Kg} / \mathrm{m}^{2}\right)$. Median BMI was $23.5 \mathrm{Kg} / \mathrm{m}^{2}$ [12.5$43.3 \mathrm{Kg} / \mathrm{m}^{2}$ ]. Most lesions were localized on the lower third of oesophagus (49\%). EUS was performed on 62 patients and lymph node invasion was suspected in $62 \%$ of cases $(\mathrm{n}=38)$. PET was performed in 20 patients (16\%).

Neo-adjuvant CT was administered to 25 patients (21\%) and CRT to 12 patients (10\%). Clinical response was obtained in $76 \%$ of cases $(n=28)$.

\section{Operative results}

Median length of procedures was 340 minutes [185-525 minutes]. Fifteen percent of patient required blood transfusion. Median length of oro-tracheal intubation was 8.3 hours [5.70-14.3 hours].

\section{Postoperative results}

Median length of stay was 17 days [8-109 days]. Postoperative mortality was $3 \%$ with $15 \%$ of major complication (> 3 Clavien Dindo classification) (Table 1). Main complications were respiratory complications (15\%). Anastomotic fistula rate was $6.6 \%(n=8)$.

\section{Pathological findings}

Adenocarcinoma was found in $62 \%$ of cases and squamous cell carcinoma in $38 \%$. Complete resection was obtained in $79 \%$ of patients. Most R1 resections were because of positive circumferential resection margin (17\%). Inferior longitudinal margin was positive in one patient $(0.8 \%)$ and superior longitudinal margin in two patients (1.7\%). On histopathological assessment of the resected specimens, the pT stage was: pT0 (5\%), pTis (5\%), pT1 (24\%), pT2 (18\%), pT3 (46\%) and pT4 (3\%). Most lesions were moderately or well differentiated (68\%). Lymph node involvement was present in $49 \%$ of cases with median number of resected lymph node of 15 [4-43]. Median lymph node ratio was 0.14 [0-0.9].

\section{Overall survival}

Four patients were lost of follow-up after a median follow-up of 47 months [28-67 months] and were kept in the study. After a median follow-up of 58 months [48.4-69.1 months], 57 patients have died. The 1- and 5 -year overall survival probabilities were $86.9 \%(95 \%$ $\mathrm{CI}=[79.5 ; 91.7])$ and $49.0 \%(95 \% \mathrm{CI}=[38.3 ; 58.8])$.

\section{Relapse free survival}

Fifty three patients $(44 \%)$ presented recurrence during follow-up with a median delay of 10.3 months [2.4-47.5 months] without any difference according to the type of recurrence. The 1- and 5-years relapse free survival rates were respectively $73 \%(95 \% \mathrm{CI}=[64 ; 80 \%])$ and $51 \%(95 \%$ $\mathrm{CI}=[46 ; 65 \%]$ ) (Figure 1). Local recurrence was the most frequent first event type $(n=30,56 \%)$. Among them, 10 patients presented cervical recurrence. Distant and disseminated recurrence occurred respectively in 17 patients (32\%) and 6 patients (11\%). Most recurrences occurred during the first year (58\%) and none after the fourth year of follow-up. Median survival in case of recurrence was 6.7 months [1-36 months] for local recurrence and 9.8 months [2.1: 44] for distant recurrence.

Based on univariate analysis, several risk factors for recurrence were identified (Table 2). Thus, age above 60 years $(\mathrm{p}=0.04)$, loss of weight greater than $10 \%(\mathrm{p}=$ $0.038)$, preoperative tumor stenosis $(\mathrm{p}<0.0001)$, EUS positive lymph node $(\mathrm{p}=0.023)$, oesophagogastric junction location of tumor $(\mathrm{p}=0.005)$, poor tumor differentiation $(\mathrm{p}=0.031), \mathrm{pT}$ stage $>2 \quad(\mathrm{p}<0.0001)$, positive lymph node status $(\mathrm{p}<0.0001)$, incomplete resection $(\mathrm{p}=$ $0.002)$, positive circumferential margin $(\mathrm{p}=0.0019)$, 
Table 1 Perioperative data

\begin{tabular}{|c|c|c|c|c|c|}
\hline & $\mathrm{n}$ & $\%$ & & $n$ & $\%$ \\
\hline Total & 120 & 100 & Total & 120 & 100 \\
\hline Preoperative data & & & Histopathological findings & & \\
\hline Age (years) & & & Histology & & \\
\hline$-\leq 60$ & 46 & 38 & - Adenocarcinoma & 75 & 62 \\
\hline$->60$ & 74 & 62 & - Squamous cell carcinoma & 45 & 38 \\
\hline Sex & & & pT stage & & \\
\hline - Male & 97 & 81 & -0 & 6 & 5 \\
\hline - Female & 23 & 19 & - is & 6 & 5 \\
\hline Weight loss & & & -1 & 29 & 24 \\
\hline$-\leq 10 \%$ & 96 & 80 & -2 & 21 & 18 \\
\hline - > 10\% & 24 & 20 & -3 & 55 & 46 \\
\hline Body Mass Index $\left(\mathrm{Kg} / \mathrm{m}^{2}\right)$ & & & -4 & 3 & 3 \\
\hline$-\geq 25$ & 74 & 62 & pN stage & & \\
\hline$-<25$ & 46 & 38 & -0 & 61 & 51 \\
\hline ASA Score & & & $-1,2$ or 3 & 59 & 49 \\
\hline-1 & 51 & 43 & Number of positive lymph nodes & & \\
\hline-2 & 39 & 33 & -0 & 61 & 51 \\
\hline-3 & 30 & 25 & $-1-4$ & 34 & 28 \\
\hline Risk factor & & & $->4$ & 25 & 21 \\
\hline - Gastro-oesophageal Reflux Disease & 44 & 37 & Lymph node ratio & & \\
\hline - Alcohol & 71 & 59 & $-\leq 0.2$ & 88 & 73 \\
\hline - Tobacco & 32 & 27 & $->0.2$ & 32 & 27 \\
\hline Localisation & & & pM stage & & \\
\hline - Oesophagogastric junction & 32 & 27 & -0 & 117 & 98 \\
\hline - Lower third oesophagus & 59 & 49 & -1 & 3 & 3 \\
\hline - Mid third oesophagus & 29 & 24 & Differentiation & & \\
\hline Tumor stenosis & & & - undiff./poorly & 23 & 21 \\
\hline - None & 51 & 43 & - moderately/well & 88 & 79 \\
\hline - Incomplete & 53 & 44 & Resection & & \\
\hline - Complete & 16 & 13 & $-\mathrm{RO}$ & 95 & 79 \\
\hline TDM lymph node & & & $-\mathrm{R} 1$ & 24 & 20 \\
\hline - No pathol. lymph node & 93 & 77 & $-\mathrm{R} 2$ & 1 & 1 \\
\hline - Pathol. lymph node & 27 & 23 & Circumferential margin & & \\
\hline EUS results & & & - Complete & 99 & 83 \\
\hline usT & 60 & & - Incomplete & 21 & 17 \\
\hline$-1 \& 2$ & 33 & 55 & Node capsular penetration & & \\
\hline$-3 \& 4$ & 27 & 45 & - No & 115 & 96 \\
\hline usN & 60 & & - Yes & 5 & 4 \\
\hline-0 & 23 & 38 & Angiolymphatic invasion & & \\
\hline-1 & 38 & 62 & - No & 58 & 60 \\
\hline Preoperative treatment & & & - Yes & 39 & 40 \\
\hline - None & 83 & 69 & Neural invasion & & \\
\hline - Chemotherapy & 25 & 21 & $-\mathrm{No}$ & 54 & 57 \\
\hline
\end{tabular}


Table 1 Perioperative data (Continued)

\begin{tabular}{lccc}
\hline - Chemo radiotherapy & 12 & 10 & - Yes \\
Postoperative data & & & 40 \\
30-day morbidity & 53 & 44 & \\
- major & 18 & 15 & \\
- minor & 35 & 29 & \\
30-day mortality & 4 & 3 & \\
\hline
\end{tabular}

node capsular penetration $(\mathrm{p}=0.021)$, angiolymphatic invasion ( $\mathrm{p}<0.0001)$, neural invasion $(\mathrm{p}<0.0001)$, high number of positive lymph nodes $(\mathrm{p}<0.0001)$ and lymph node ratio $>0.2(\mathrm{p}<0.0001)$ were significantly associated with a poorer RFS.

Results of multivariate analysis are summarized on Table 3. In the multivariate analysis for pre-operative variables (Step 1), only presence of tumor stenosis was associated with an increased risk of relapse $(\mathrm{HR}=3.36$; 95\% CI $=[1.68 ; 6.72] \mathrm{p}=0.001)$.

For pathological data (Step 2), the following variables were associated with a higher probability of relapse in multivariate analysis: pT stage $>2(\mathrm{HR}=2.91 ; 95 \%$ $\mathrm{CI}=[1.16 ; 7.31] \mathrm{p}=0.023)$, positive lymph node status $(\mathrm{HR}=4.67 ; 95 \% \mathrm{CI}=[1.47 ; 14.77] \mathrm{p}=0.009)$ and lymph node ratio $>0.2(\mathrm{HR}=2.71 ; 95 \% \mathrm{CI}=[1.34 ; 5.51] \mathrm{p}=0.006)$.

When combining pre-operative and pathological variables statistically significative in the two previous multivariate analysis (Step 3), the following variables were associated with an increased risk of relapse: pT stage $>2$ $(\mathrm{HR}=2.42 ; 95 \% \mathrm{CI}=[1.22 ; 4.79] \mathrm{p}=0.011)$, positive lymph node status $(\mathrm{HR}=3.69 ; 95 \% \mathrm{CI}=[1.53 ; 8.96] \mathrm{p}=0.004)$ and lymph node ratio $>0.2(\mathrm{HR}=2.57 ; 95 \% \mathrm{CI}=[1.38$;
4.76] $\mathrm{p}=0.003)$. Relapse free survivals according to the number of risk factors were presented on Figure $2(\mathrm{p}<$ 0.0001). Addition of risks factors was correlated with a poorer RFS.

\section{Competing risks analysis}

In multivariate analysis (Table 3), only the presence of preoperative tumor stenosis was associated with an increased risk of local recurrence $(\mathrm{HR}=3.46 ; 95 \% \mathrm{CI}=$ $[1.38 ; 8.70] \mathrm{p}=0.008)$. There was a trend for presence of positive lymph node $(\mathrm{HR}=6.01 ; 95 \% \mathrm{CI}=[0.84 ; 43.10]$ $\mathrm{p}=0.074$ ) that did not reach statistical significance. Concerning distant recurrence (Table 3 ), only the presence of poor or undifferentiated tumor was associated with a higher probability of distant recurrence $(\mathrm{HR}=3.32$; $95 \%$ $\mathrm{CI}=[1.03 ; 10.04] \mathrm{p}=0.044)$.

\section{Discussion}

Several studies have identified different risk factors of tumor recurrence after surgery of oesophageal cancer. Positive lymph node status is the most frequent factor identified [7-9]. It is also highlighted as an independent risk factor in our study. However, the impact of lymph

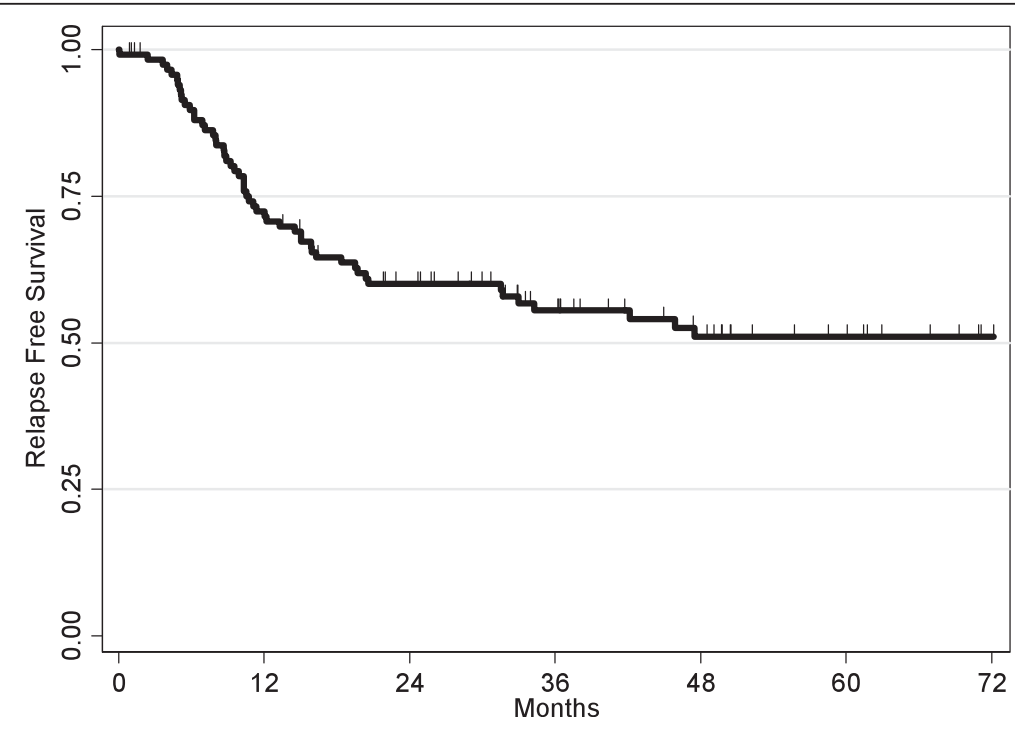

Figure 1 Kaplan-Meier Relapse Free Survival curve. 
Table 2 Relapse free survival - univariate analysis

\begin{tabular}{|c|c|c|}
\hline Preoperative data & $\% 5-y$ RFS (n) (n total = 120) & $\mathrm{p}$ \\
\hline Age (years) : <60 / >60 & $58.6(16) / 45.6(37)$ & 0.0396 \\
\hline ASA score : 1-2/3 & $50.0(41) / 55.1(12)$ & 0.6742 \\
\hline Sex: Male / Female & $48.5(46) / 61.8(7)$ & 0.1641 \\
\hline Histology : Adenocarcinoma / Squamous cell carcinoma & $53.9(34) / 43.0(19)$ & 0.7995 \\
\hline Weight loss (\%) : $\leq 10 />10$ & $56.3(38) / 29.2(15)$ & 0.0379 \\
\hline Body Mass Index $\left(\mathrm{Kg} / \mathrm{m}^{2}\right): \leq 25 />25$ & $51.2(32) / 49.4(21)$ & 0.597 \\
\hline Gastro-oesophageal reflux disease : No / Yes & $45.5(36) / 60.4(17)$ & 0.2185 \\
\hline Tumor stenosis : No / Yes & $77.9(11) / 31.8(42)$ & $<0.0001$ \\
\hline TDM pathological lymph node : No / Yes & $56.0(37) / 33.7(16)$ & 0.063 \\
\hline \multicolumn{3}{|l|}{ EUS results } \\
\hline usT : $1 \& 2 / 3 \& 4$ & $72.5(9) / 52.0(11)$ & 0.1727 \\
\hline usN : $0 / 1$ & $78.1(4) / 51.7(16)$ & 0.0227 \\
\hline Preoperative treatment : No / CT or CRT & $51.9(37) / 49.2(16)$ & 0.7166 \\
\hline Tumor localization : Oesophagogastric jct. / Lower or mid third & $40.2(18) / 58.9(35)$ & 0.0046 \\
\hline Postoperative data & $\%$ 5-y RFS (n) & $\mathrm{p}$ \\
\hline Differentiation: Undiff. or poorly diff. / Moderately or well diff. & $40.9(13) / 55.6(35)$ & 0.0313 \\
\hline pT Stage : $T \leq 2 / T>2$ & $75.9(13) / 24.9(40)$ & $<0.0001$ \\
\hline pN Stage : No / N+ & $82.9(9) / 16.7(44)$ & $<0.0001$ \\
\hline Resection : R0 / R1 or R2 & $57.2(37) / 25.0(16)$ & 0.002 \\
\hline Circumferential margin : Complete / Incomplete & $56.9(39) / 19.6(14)$ & 0.0019 \\
\hline Node capsular penetration : No/Yes & $52.4(49) / 20.0(4)$ & 0.0206 \\
\hline Angiolymphatic invasion : No / Yes & $66.4(17) / 19.4(29)$ & $<0.0001$ \\
\hline Neural invasion : No / Yes & $66.5(16) / 25.5(28)$ & $<0.0001$ \\
\hline Number of positive lymph nodes : $0 / 1-4 />4$ & $82.9(9) / 23.4(23) / 7.8(21)$ & $<0.0001$ \\
\hline Lymph node ratio : $\leq 0.2 />0.2$ & $66.5(26) / 0.0(27)$ & $<0.0001$ \\
\hline
\end{tabular}

node involvement can be refined by studying the prognostic role of lymph node ratio ie ratio between positive lymph nodes and resected lymph nodes. Ratios varying from 0.1 to 0.5 have already been discussed $[8,10]$. In this study, ratio was set at 0.2 , low enough to be discriminating. It turns out to be an independent major risk factor for relapse free survival that can be illustrated by a 5 -year RFS of $67 \%$ with a ratio $\leq 0.2$ versus $0 \%$ with a ratio $>0.2$. An interesting finding of our study is the independency of lymph node ratio as a risk factor, particularly independent from lymph node positivity what could have been a confusing factor.

Other authors have also identified the number of involved nodes as a prognostic factor $[9,11]$. These studies show the importance of node involvement as a quantitative and not only qualitative factor and are behind the recent changes to the 2009 UICC TNM classification. This last distinguishes nowadays different stages of nodal involvement for oesophageal cancer, superimposed on the oesophagogastric junction cancer classification, whereas it included only a single stage of nodal involvement in the previous version [12].

Unfortunately, information on the presence of this major prognostic factor is only obtained retrospectively on specimen examination. It does not allow optimal adaptation of neo-adjuvant treatment. Current diagnostic methods combining computed tomography, EUS and endoscopy permit an appropriate staging in 56\% of cases and adjunction of PET does not provide better sensitivity for the preoperative lymph node diagnosis compared to EUS or computed tomography (sensitivity of 0.57 vs 0.8 and 0.5 resp.) [13,14].

Indication of adjuvant treatment after oesophageal surgery is not recommended even in case of lymph node involvement but may be discussed if the patient is healthy, demanding, and informed. However, lymph node invasion seems to be a very accurate predictor of relapse free survival and may be used to identify patients requiring adjuvant chemotherapy or chemoradiotherapy to treat systemic metastases developing after primary resection [15]. 
Table 3 Relapse Free Survival - Multivariate analysis

\begin{tabular}{|c|c|c|c|c|c|c|c|c|c|c|c|}
\hline \multirow{2}{*}{\multicolumn{3}{|c|}{$\begin{array}{c}\text { Cox Model } \\
\text { Relapse Free Survival }\end{array}$}} & \multicolumn{6}{|c|}{ Competing risks \& Fine $\&$ Gray } & \multirow{2}{*}{\multicolumn{3}{|c|}{$\begin{array}{c}\text { Cox RFS } \\
\text { Step 3: Final analysis }\end{array}$}} \\
\hline & & & \multicolumn{3}{|c|}{ Local recurrence } & \multicolumn{3}{|c|}{ Distant recurrence } & & & \\
\hline HR & $95 \% \mathrm{Cl}$ & $\mathrm{p}$ & HR & $95 \% \mathrm{Cl}$ & $\mathrm{p}$ & HR & $95 \% \mathrm{Cl}$ & $\mathrm{p}$ & HR & $95 \% \mathrm{Cl}$ & $p$ \\
\hline \multicolumn{11}{|c|}{ Step 1 : Preoperative data } & \\
\hline
\end{tabular}

\begin{tabular}{|c|c|c|c|c|c|c|c|c|c|c|c|c|}
\hline \multicolumn{13}{|l|}{ Weight loss (\%) } \\
\hline$-\leq 10$ & 1 & & & 1 & & & 1 & & & & & \\
\hline$->10$ & 1.17 & $0.63 ; 2.19$ & 0.615 & 0.81 & $0.34 ; 1.94$ & 0.648 & 1.74 & $0.72 ; 4.22$ & 0.218 & & & \\
\hline \multicolumn{13}{|l|}{ Age (years) } \\
\hline$-<60$ & 1 & & & 1 & & & 1 & & & & & \\
\hline$->60$ & 1.79 & $0.99 ; 3.23$ & 0.051 & 1.13 & $0.55 ; 2.32$ & 0.731 & 2.4 & $0.91 ; 6.34$ & 0.076 & & & \\
\hline \multicolumn{13}{|l|}{ Tumor stenosis } \\
\hline - No & 1 & & & 1 & & & 1 & & & 1 & & \\
\hline \multirow[t]{2}{*}{ - Yes } & 3.36 & $1.68 ; 6.72$ & 0.001 & 3.46 & $1.38 ; 8.70$ & 0.008 & 2.21 & $0.78 ; 6.23$ & 0.135 & 1.12 & $0.54 ; 2.39$ & 0.757 \\
\hline & & Ste & 2 : Pat & nologi & findings & & & & & & & \\
\hline Tumor localization & & \\
\hline - Oesophagogastric jct & 1.16 & $0.55 ; 2.45$ & 0.689 & 1.27 & $0.51 ; 3.16$ & 0.61 & 0.92 & $0.30 ; 2.78$ & 0.879 & & & \\
\hline - Lower/mid third & 1 & & & 1 & & & 1 & & & & & \\
\hline \multicolumn{13}{|l|}{ Differentiation } \\
\hline - undiff./poorly & 1.03 & $0.47 ; 2.28$ & 0.933 & 0.32 & $0.07 ; 1.33$ & 0.116 & 3.22 & $1.03 ; 10.04$ & 0.044 & & & \\
\hline - moderately/well & 1 & & & 1 & & & 1 & & & & & \\
\hline \multicolumn{13}{|l|}{ T Stage } \\
\hline$-\mathrm{pT} \leq 2$ & 1 & & & 1 & & & 1 & & & 1 & & \\
\hline - pT > 2 & 2.91 & $1.16 ; 7.31$ & 0.023 & 1.03 & $0.28 ; 3.82$ & 0.955 & 5.86 & $0.93 ; 37.15$ & 0.06 & 2.42 & $1.22 ; 4.79$ & 0.011 \\
\hline \multicolumn{13}{|l|}{ N Stage } \\
\hline - pNo & 1 & & & 1 & & & 1 & & & 1 & & \\
\hline$-\mathrm{pN}+$ & 4.67 & $1.47 ; 14.77$ & 0.009 & 6.01 & $0.84 ; 43.10$ & 0.074 & 3.48 & $0.68 ; 17.81$ & 0.135 & 3.69 & $1.53 ; 8.96$ & 0.004 \\
\hline \multicolumn{13}{|l|}{ Resection } \\
\hline$-\mathrm{RO}$ & 1 & & & 1 & & & 1 & & & & & \\
\hline - R1 or R2 & 0.52 & $0.24 ; 1.13$ & 0.098 & 0.99 & $0.35 ; 2.74$ & 0.98 & 0.4 & $0.11 ; 1.48$ & 0.174 & & & \\
\hline \multicolumn{13}{|l|}{ Lymph node ratio } \\
\hline$-\leq 0.2$ & 1 & & & 1 & & & 1 & & & 1 & & \\
\hline$->0.2$ & 2.71 & $1.34 ; 5.51$ & 0.006 & 1.25 & $0.46 ; 3.44$ & 0.659 & 2.45 & $0.81 ; 7.38$ & 0.112 & 2.57 & $1.38 ; 4.76$ & 0.003 \\
\hline \multicolumn{13}{|l|}{ Angiolymph. invasion } \\
\hline$-\mathrm{No}$ & 1 & & & 1 & & & 1 & & & & & \\
\hline - Yes & 1.98 & $0.96 ; 4.09$ & 0.066 & 1.7 & $0.58 ; 5.01$ & 0.329 & 0.95 & $0.33 ; 2.75$ & 0.927 & & & \\
\hline \multicolumn{13}{|l|}{ Neural invasion } \\
\hline - No & 1 & & & 1 & & & 1 & & & & & \\
\hline - Yes & 1.14 & $0.55 ; 2.38$ & 0.729 & 1.3 & $0.43 ; 3.91$ & 0.64 & 0.77 & $0.22 ; 2.67$ & 0.684 & & & \\
\hline
\end{tabular}

Tumor depth, defined with pT stage, was also found as an independent prognostic factor in our study. Depth invasion has also been described in several other studies as a prognostic factor independent of nodal status $[16,17]$. Similarly, the importance of tumor length or its development location have been described [18].

Preoperative tumor stenosis was found in our study to be an independent risk factor of local relapse that, to our knowledge, has never been previously reported. This is the main new factor identified in our study. The interest of this factor, simply defined on endoscopic and/or barium swallow criteria, is its preoperative availability. Despite its clear clinical correlation with a high pT stage, quality of resection but also with nutritional status, it appears, statistically, to be an independent risk for local relapse and not for distant relapse. It could represent an 


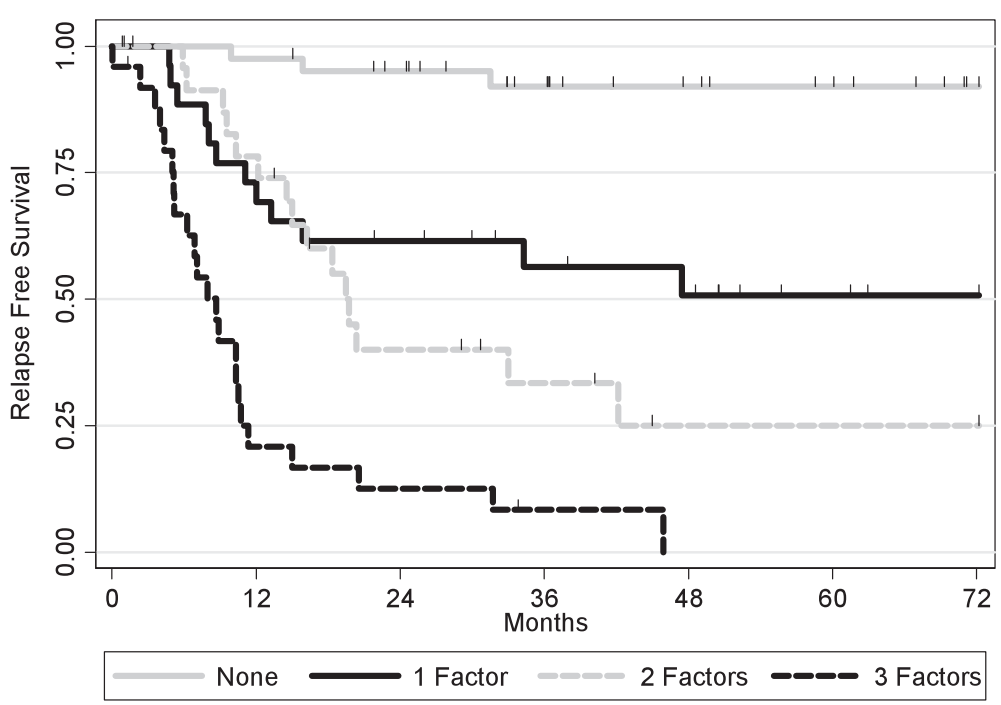

Figure 2 Kaplan-Meier Relapse Free Survival curves according to the number of risk factors $(p<0.001)$.

additional argument in the discussion of either preoperative chemoradiotherapy or in the indication of transthoracic vs transhiatal approach to get an optimal local disease control. Indeed, there is evidence that preoperative chemoradiotherapy increases the rate of complete resection i.e. local control for patients with locally advanced disease even if this was not always translated into a survival benefit in individual studies $[19,20]$. Similarly, transthoracic approach allows greater lymphadenectomy (eight more lymph node retrieved compared with transhiatal approach) [21] that might provide increased local control and disease free survival [22].

Several other risk factors of recurrence, very different, have been described as circumferential margin involvement $[23,24]$, involvement of subcarinal and lower paraoesophageal lymph nodes [25], tumor-stroma ratio [26], endoscopic tumor length [27], good performance status of the patient [28]. Even if tumor stage and lymph node ratio are probably the most relevant risk factors of recurrence, this kind of studies, as ours, are necessary to refine oesophagus cancer prognosis and to help in the decision for adjuvant therapy.

Locoregional recurrence has been described with longer survival than distant or disseminated recurrence particularly in case of cervical recurrence [29,30]. On the other hand, Bhansali et al. [31] reported no difference in different types of recurrence. In our report, survival in case of local recurrence was surprisingly 3 months shorter than for distant recurrence. This is probably due to differences in treatment protocol after relapse.

Half of our patients presented with $\mathrm{pT}<3$ or negative preoperative lymph node status. That partly explains our low rate of patient who received preoperative treatment (30\%). Moreover, the length of our study, begun in 1998, is another explanation, first main studies of neo-adjuvant treatment still not published at that time. Finally, low rate of $50 \%$ of preoperative EUS performed may have led to a preoperative downstaging and also explains the rate of preoperative treatment.

A same approach was performed with overall survival and brought similar results. As our study focused on recurrence risk, these results are not detailed here. Five year overall survival estimated by Kaplan Meier method was $49 \%$ in our survey. This result, higher than OS reported in literature [1], may be due to our high rate of low stage tumors and drastic patient selection for surgical treatment.

Adenocarcinoma and squamous cell carcinoma were both included in this study that may be a bias. Indeed, Siewert et al. [32] reported two different diseases with different pathogenesis, epidemiology, tumor biology and prognosis requiring different therapeutic strategies. However, focusing on relapse and survival, several studies comparing adenocarcinoma and squamous cell carcinoma have reported worse, similar or better survival according to histopathology [33-35]. In our study, histopathology doesn't appear to be correlated to RFS and OS and multivariate analysis allowed us to statistically study all of our patients in the same cohort. Signet ring cell adenocarcinoma is well known to have poorer prognosis [36]. Our number of patient and particularly with signet ring cell was too small to study it as a risk factor.

This study might initiate thinking for patients who received neoadjuvant treatment as indicated in guidelines, if they could benefit, in presence of these risks factors, of post-operative treatment or of a more intensive clinical or radiological follow-up. Moreover, recurrence risk is directly correlated with the number of positive 
risk factors (pN stage, $\mathrm{pT}$ stage and lymph node ratio), creating a risk score of recurrence, what may ponder discussion according to this score. Our score has to be confirmed by others studies but strongly argue for adjuvant therapy in case of cumulated risks, particularly in case of tumor regression after preoperative treatment.

Limitations of this study are numerous. The main is it retrospective type, while conducted on a homogeneous group of patients, that has led to heterogeneity in preoperative administrated treatments. These results have to be confirmed in a prospective one with standardized protocols. Then, monocentric aspect of the study allowed us to analyze patients with standardized practices but represents also a bias as the results must be confirmed in multicentric studies. Besides, our department is not a high volume center for oesophageal surgery, due to a low incidence of oesophageal cancer in our county, but belongs to the university hospital and is experienced in oesophagogastric surgery.

\section{Conclusion}

Finally, our study demonstrates that preoperative tumor stenosis is the only prognostic factor associated with an increased risk of local relapse. Concerning relapse free survival, pT stage $>2$, positive lymph node status and lymph node ratio $>0.2$ are independent prognostic factors of recurrence after Ivor-Lewis surgery for cancer. Furthermore, addition of these risk factors is correlated with an increasing risk of recurrence. Thus, a routine postoperative treatment or reinforced follow-up should probably be considered in patients combining these risk factors.

\section{Consents}

Written informed consent was obtained from the patients included or their family for the publication of this study.

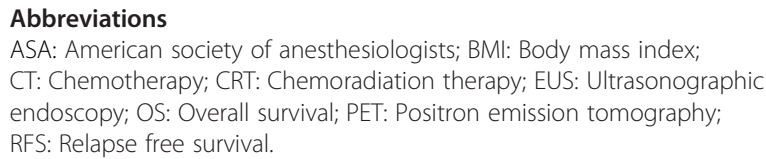

Abbreviations

ASA: American society of anesthesiologists; BMI: Body mass index; CT: Chemotherapy; CRT: Chemoradiation therapy; EUS: Ultrasonographic endoscopy; OS: Overall survival; PET: Positron emission tomography; RFS: Relapse free survival.

\section{Competing interests}

The authors declare that they have no competing interests.

\section{Authors' contributions}

MCR was responsible for the acquisition, analysis and interpretation of data, and wrote the manuscript. NC supervised the study, and assisted in writing the manuscript. TF was responsible for the statistical analysis. $\mathrm{BB}, \mathrm{MH}, \mathrm{CHJ}$, EB, LG, SK, GP and BP assisted in data acquisition. All authors read and approved the final manuscript.

\section{Acknowledgements}

Corneliu Voronca, and Thierry Chaubard participated in performing oesophagectomies and assisted in data acquisition.

\section{Author details}

'Department of Digestive Surgery, Toulouse Purpan University Hospital,

Toulouse III University, place du Dr Baylac, 31059 Toulouse, France.
2Department of Biostatistics, Institut Claudius Regaud, 20-24 rue du Pont Saint Pierre, 31052 Toulouse, France.

Received: 10 March 2013 Accepted: 28 October 2013

Published: 21 November 2013

\section{References}

1. Burmeister BH, Smithers BM, Gebski V, Fitzgerald L, Simes RJ, Devitt P, Ackland S, Gotley DC, Joseph D, Millar J, North J, Walpole ET, Denham JW: Surgery alone versus chemoradiotherapy followed by surgery for resectable cancer of the oesophagus: a randomised controlled phase III trial. Lancet Oncol 2005, 6:659-668.

2. Bedenne L, Michel P, Bouche O, Milan C, Mariette C, Conroy T, Pezet D, Roullet B, Seitz JF, Herr JP, Paillot B, Arveux P, Bonnetain F, Binquet C: Chemoradiation followed by surgery compared with chemoradiation alone in squamous cancer of the esophagus: FFCD 9102. J Clin Oncol 2007, 25:1160-1168.

3. Stahl M, Stuschke M, Lehmann N, Meyer HJ, Walz MK, Seeber S, Klump B, Budach W, Teichmann R, Schmitt M, Schmitt G, Franke C, Wilke H: Chemoradiation with and without surgery in patients with locally advanced squamous cell carcinoma of the esophagus. J Clin Oncol 2005, 23:2310-2317.

4. Pera M: Epidemiology of esophageal cancer, especially adenocarcinoma of the esophagus and esophagogastric junction. Recent Results Cancer Res 2000, 155:1-14.

5. Sjoquist KM, Burmeister BH, Smithers BM, Zalcberg JR, Simes RJ, Barbour A, Gebski V: Survival after neoadjuvant chemotherapy or chemoradiotherapy for resectable oesophageal carcinoma: an updated meta-analysis. Lancet Oncol 2011, 12:681-692.

6. Lledo G, Barrioz T, Landi B, Mariette C, Maingon P, Raoul JL, Rougier P, Seitz JF, Triboulet JP: Thésaurus National de Cancérologie digestive - Société Nationale Française de Gastro-Entérologie. 2013. http://www.snfge.asso.fr/ data/ModuleDocument/publication/5/pdf/TNCD-chapitre-1.pdf]

7. Akutsu $\mathrm{Y}$, Matsubara $\mathrm{H}$ : The significance of lymph node status as a prognostic factor for esophageal cancer. Surg Today 2011, 41:1190-1195.

8. Liu YP, Ma L, Wang SJ, Chen YN, Wu GX, Han M, Wang XL: Prognostic value of lymph node metastases and lymph node ratio in esophageal squamous cell carcinoma. Eur J Surg Oncol 2010, 36:155-159.

9. Mariette C, Piessen G, Briez N, Triboulet JP: The number of metastatic lymph nodes and the ratio between metastatic and examined lymph nodes are independent prognostic factors in esophageal cancer regardless of neoadjuvant chemoradiation or lymphadenectomy extent. Ann Surg 2008, 247:365-371.

10. Tachibana M, Dhar DK, Kinugasa S, Kotoh T, Shibakita M, Ohno S, Masunaga R, Kubota $H$, Nagasue N: Esophageal cancer with distant lymph node metastasis: prognostic significance of metastatic lymph node ratio. J Clin Gastroenterol 2000, 31:318-322.

11. Hu Y, Hu C, Zhang H, Ping Y, Chen LQ: How does the number of resected lymph nodes influence TNM staging and prognosis for esophageal carcinoma? Ann Surg Oncol 2010, 17:784-790.

12. Sobin L, Gospodarowicz M, Wittekind C: TNM classification of malignant tumours. 7th edition. New York: Wiley-Blackwell; 2009

13. Nishimaki T, Tanaka O, Ando N, Ide H, Watanabe H, Shinoda M, Takiyama W, Yamana H, Ishida K, Isono K, Endo M, Ikeuchi T, Mitomi T, Koizumi H, Imamura M, lizuka T: Evaluation of the accuracy of preoperative staging in thoracic esophageal cancer. Ann Thorac Surg 1999, 68:2059-2064.

14. van Vliet EP, Heijenbrok-Kal MH, Hunink MG, Kuipers EJ, Siersema PD: Staging investigations for oesophageal cancer: a meta-analysis. Br J Cancer 2008, 98:547-557.

15. Hagen JA, DeMeester SR, Peters JH, Chandrasoma P, DeMeester TR: Curative resection for esophageal adenocarcinoma: analysis of 100 en bloc esophagectomies. Ann Surg 2001, 234:520-530. discussion 530-521.

16. Khan OA, Fitzgerald JJ, Soomro I, Beggs FD, Morgan WE, Duffy JP: Prognostic significance of circumferential resection margin involvement following oesophagectomy for cancer. Br J Cancer 2003, 88:1549-1552.

17. Wijnhoven BP, Tran KT, Esterman A, Watson DI, Tilanus HW: An evaluation of prognostic factors and tumor staging of resected carcinoma of the esophagus. Ann Surg 2007, 245:717-725.

18. Hosokawa Y, Kinoshita T, Konishi M, Takahashi S, Gotohda N, Kato Y, Daiko H, Nishimura M, Katsumata K, Sugiyama Y, Kinoshita T: Clinicopathological features and prognostic factors of Adenocarcinoma of the Esophagogastric 
junction according to Siewert classification: experiences at a single institution in Japan. Ann Surg Oncol 2012, 19:677-683.

19. Burmeister BH, Thomas JM, Burmeister EA, Walpole ET, Harvey JA, Thomson DB, Barbour AP, Gotley DC, Smithers BM: Is concurrent radiation therapy required in patients receiving preoperative chemotherapy for adenocarcinoma of the oesophagus? A randomised phase II trial. Eur J Cancer 2011, 47:354-360.

20. Courrech Staal EF, Aleman BM, Boot $\mathrm{H}$, van Velthuysen ML, van Tinteren $\mathrm{H}$, van Sandick JW: Systematic review of the benefits and risks of neoadjuvant chemoradiation for oesophageal cancer. Br J Surg 2010, 97:1482-1496.

21. Boshier PR, Anderson O, Hanna GB: Transthoracic versus transhiatal esophagectomy for the treatment of esophagogastric cancer: a meta-analysis. Ann Surg 2011, 254:894-906.

22. Omloo JM, Lagarde SM, Hulscher JB, Reitsma JB, Fockens $P$, van Dekken $H$, Ten Kate FJ, Obertop H, Tilanus HW, van Lanschot JJ: Extended transthoracic resection compared with limited transhiatal resection for adenocarcinoma of the mid/distal esophagus: five-year survival of a randomized clinical trial. Ann Surg 2007, 246:992-1000. discussion 1000-1001.

23. Mulligan ED, Dunne B, Griffin M, Keeling N, Reynolds JV: Margin involvement and outcome in oesophageal carcinoma: a 10-year experience in a specialist unit. Eur J Surg Oncol 2004, 30:313-317.

24. Saha AK, Sutton C, Rotimi O, Dexter S, Sue-Ling H, Sarela Al: Neoadjuvant chemotherapy and surgery for esophageal adenocarcinoma: prognostic value of circumferential resection margin and stratification of N1 category. Ann Surg Oncol 2009, 16:1364-1370.

25. Tanaka H, Ohira M, Kubo N, Muguruma K, Yamashita Y, Sawada T, Hirakawa K: Association of location of lymph node metastases with postoperative recurrence of esophageal squamous cell carcinoma. Anticancer Res 2012, 32:3421-3426

26. Wang K, Ma W, Wang J, Yu L, Zhang X, Wang Z, Tan B, Wang N, Bai B, Yang S, Liu H, Zhu S, Cheng Y: Tumor-stroma ratio is an independent predictor for survival in esophageal squamous cell carcinoma. J Thorac Oncol 2012, 7:1457-1461.

27. Wang BY, Liu CY, Lin CH, Hsu PK, Hsu WH, Wu YC, Cheng CY: Endoscopic tumor length is an independent prognostic factor in esophageal squamous cell carcinoma. Ann Surg Oncol 2012, 19:2149-2158.

28. Lee PC, Mirza FM, Port JL, Stiles BM, Paul S, Christos P, Altorki NK: Predictors of recurrence and disease-free survival in patients with completely resected esophageal carcinoma. J Thorac Cardiovasc Surg 2011, 141:1196-1206.

29. Dresner SM, Wayman J, Shenfine J, Harris A, Hayes N, Griffin SM: Pattern of recurrence following subtotal oesophagectomy with two field lymphadenectomy. Br J Surg 2000, 87:362-373.

30. Mariette C, Balon JM, Piessen G, Fabre S, Van Seuningen I, Triboulet JP: Pattern of recurrence following complete resection of esophageal carcinoma and factors predictive of recurrent disease. Cancer 2003, 97:1616-1623.

31. Bhansali MS, Fujita H, Kakegawa T, Yamana H, Ono T, Hikita S, Toh Y, Fujii T, Tou U, Shirouzu K: Pattern of recurrence after extended radical esophagectomy with three-field lymph node dissection for squamous cell carcinoma in the thoracic esophagus. World J Surg 1997, 21:275-281.

32. Siewert JR, Ott K: Are squamous and adenocarcinomas of the esophagus the same disease? Semin Radiat Oncol 2007, 17:38-44.

33. Lieberman MD, Shriver CD, Bleckner S, Burt M: Carcinoma of the esophagus. Prognostic significance of histologic type. J Thorac Cardiovasc Surg 1995, 109:130-138. discussion 139.

34. Lund O, Hasenkam JM, Aagaard MT, Kimose HH: Time-related changes in characteristics of prognostic significance in carcinomas of the oesophagus and cardia. Br J Surg 1989, 76:1301-1307.

35. Siewert JR, Stein HJ, Feith M, Bruecher BL, Bartels H, Fink U: Histologic tumor type is an independent prognostic parameter in esophageal cancer: lessons from more than 1,000 consecutive resections at a single center in the Western world. Ann Surg 2001, 234:360-367. discussion 368-369.

36. Piessen $G$, Messager $M$, Leteurtre $E$, Jean-Pierre $T$, Mariette $C$ : Signet ring cell histology is an independent predictor of poor prognosis in gastric adenocarcinoma regardless of tumoral clinical presentation. Ann Surg 2009, 250:878-887.

doi:10.1186/1749-8090-8-215

Cite this article as: du Rieu et al:: Recurrence risk after Ivor Lewis oesophagectomy for cancer. Journal of Cardiothoracic Surgery 2013 8:215.

\section{Submit your next manuscript to BioMed Central and take full advantage of:}

- Convenient online submission

- Thorough peer review

- No space constraints or color figure charges

- Immediate publication on acceptance

- Inclusion in PubMed, CAS, Scopus and Google Scholar

- Research which is freely available for redistribution

Submit your manuscript at www.biomedcentral.com/submit
() Biomed Central 